\title{
Preparation of Phosphorus Organo-Mineral Fertilizers with Prolonged Action, Based on the Aspen Bark
}

\author{
Evgenia V. Veprikova*, Mikhail Yu. Belash, \\ Nicolay V. Chesnokov and Boris N. Kuznetsov \\ Institute of Chemistry and Chemical Technology SB RAS \\ FRC "Krasnoyarsk Science Center SB RAS" \\ 50/24 Akademgorodok, Krasnoyarsk, 660036, Russia
}

Received 24.05.2018, received in revised form 19.06.2018, accepted 07.09.2018

The method of preparation of phosphorus organo-mineral fertilizers with the increase resistanceto leaching of mineral componentsby waterbased on the impregnation of aspen bark by water solution of $\mathrm{KH}_{2} \mathrm{PO}_{4}$ and its transformation into low soluble compound $\mathrm{Ca}\left(\mathrm{H}_{2} \mathrm{PO}_{4}\right)_{2}$ was developed. The optimal condition of fertilizers preparation, ensuring minimum leaching of phosphates and potassium were selected. The possibility of enrichment of fertilizers by microelements $(\mathrm{Mg}, \mathrm{Cu}, \mathrm{Zn}, \mathrm{Fe})$ without the loss of their water resistance was shown. The increased resistanceof designed fertilizers on the basis of aspen bark to leaching of mineral components by water determines their prolonged action. As a result of vegetation growth experiments the stimulating effect of phosphateorgano-mineral fertilizers on the basis of aspen barkwas shown.

Keywords: aspen bark, fertilizer, phosphates, potassium, microelements, leaching by water.

Citation: Veprikova E.V., Belash M.Yu., Chesnokov N.V., Kuznetsov B.N. Preparation of phosphorus organo-mineral fertilizers with prolonged action, based on the aspen bark, J. Sib. Fed. Univ. Chem., 2018, 11(3), 377-389. DOI: 10.17516/1998-28360084 .

(C) Siberian Federal University. All rights reserved

* Corresponding author E-mail address: veprikova2@mail.ru 


\title{
Получение фосфорных органоминеральных удобрений пролонгированного действия на основе коры осины
}

\author{
Е.В. Веприкова, М.Ю. Белаш, \\ Н.В. Чесноков, Б.Н. Кузнецов \\ Институт химии и химической технологии СО РАН \\ ФИЦ «Красноярский научный центр СО РАН» \\ Россия, 660036, Красноярск, Академгородок, 50/24
}

Разработан способ получения фосфорных органоминеральных удобрений с повыменной устойчивостью к вымыванию минеральных компонентов водой, основанный на пропитке коры осины водным раствором $\mathrm{KH}_{2} \mathrm{PO}_{4}$ и его превращении в малорастворимое соединение $\mathrm{Ca}\left(\mathrm{H}_{2} \mathrm{PO}_{4}\right)_{2}$. Осуществлен подбор оптимальных условий их приготовления, обеспечивающих минимальное вымывание водой фосфатов и калия из полученных удобрений. Показана возможность обогащения удобрений микроэлементами ( $\mathrm{Mg}, \mathrm{Cu}, \mathrm{Zn}, \mathrm{Fe}$ ) без потери их водостойкости. Повышенная устойчивость разработанных удобрений на основе коры осины $\kappa$ вымыванию минеральных компонентов водой определяет их пролонгированное действие. В результате проведения вегетационных экспериментов выявлено ростостимулирующее действие фосфорных органоминеральных удобрения на основе коры осины.

Ключевые слова: кора осины, удобрение, фосфаты, калий, микроэлементы, вымывание водой.

\section{Введение}

Потенциал отходов древесной коры как сырья для получения продуктов различного назначения хорошо известен $[1,2]$. Перспективным направлением переработки коры является получение на ее основе композитных материалов различного назначения - модифицированных сорбентов, в которых кора служит носителем активного компонента [3], биокомпозитных удобрений пролонгированного действия на основе пористых подложек, которые получают в результате обработки коры водным раствором щелочи [4].

Обзор литературы выявил актуальность разработок новых видов удобрений на основе пористых носителей различной природы. Большое внимание уделяется изучению применения цеолитов в этих целях, благодаря их структуре и физико-химическим свойствам $[5,6]$. Однако с применением носителей древесной природы были получены эффективные удобрения, обладающие способностью к медленному выделению нанесенного компонента (азота) [7]. Это позволяет рассматривать древесные материалы в качестве альтернативы цеолитам. Следует отметить, что за счет высокой сорбционной активности длительное применение цеолитов способно приводить к дефициту полезных минеральных и органических веществ в почве. Это серьезный недостаток при разработке удобрений с длительным сроком действия [8]. Следует отметить, что носители из отходов древесины и коры являются источником ценных органических и минеральных веществ, поступающих в почву за счет их биоразложения. 
Одним из основных элементов, необходимых для сбалансированного развития растений, является фосфор. Создание фосфорсодержащих удобрений пролонгированного действия важно как для повышения эффективности применения удобрений, так и для снижения загрязнения почвы и грунтовых вод избытком фосфатов, к чему приводит использование традиционных водорастворимых удобрений [9]. В литературе описаны различные способы повышения водостойкости фосфорных удобрений - гранулирование [10], применение защитного покрытия [11], иммобилизация на цеолите [6].

Авторами статьи был разработан способ получения фосфорнокалийных удобрений с повышенной устойчивостью к вымыванию фосфатов и калия водой на основе пористых подложек из коры березы, сосны и лиственницы. Однако подход, использованный для повышения водостойкости, эффективен при применении в качестве фосфорнокалийной соли только $\mathrm{K}_{2} \mathrm{HPO}_{4}$. Из удобрений, содержащих $\mathrm{KH}_{2} \mathrm{PO}_{4}$, через 15 мин вымывается не менее 80,9 \% фосфатов и не менее 79,8 \% калия [12 - 14]. В работе [15] для закрепления фосфора на поверхности пористого носителя (цеолита) предложено переводить гидрофосфат натрия в гидроксиаппатит за счет обработки раствором хлорида кальция. Недостатком является присутствие фосфора в удобрении в форме ионов $\mathrm{PO}_{4}{ }^{3-}$, которые достаточно плохо усваиваются растениями. Поэтому разработка способов получения водостойких удобрений, содержащих фосфор в биодоступной форме, на основе различных солей, в частности $\mathrm{KH}_{2} \mathrm{PO}_{4}$, имеет большое значение.

Цель работы состояла в разработке способа получения органоминеральных удобрений с повышенной водостойкостью на основе подложки из коры осины и $\mathrm{KH}_{2} \mathrm{PO}_{4}$.

\section{Экспериментальная часть}

Сырьем для получения органоминеральных удобрений служила измельченная воздушносухая кора осины следующего фракционного состава, мас. \%: $(0.5-1.0)$ мм - 75; $(1,0-2,0)$ мм - 25. Массовое содержание корки и луба в полидисперсном сырье составляло 60,6 и 39,4 \%, соответственно.

Измельченную кору обрабатывали $1 \%$-ным водным раствором $\mathrm{NaOH}$ при температуре $90{ }^{\circ} \mathrm{C}$, гидромодуле 10 в течение 60 мин и перемешивании. По окончании процесса раствор щелочи отделяли фильтрованием, а полученный материал (пористую подложку) трехкратно промывали водой при комнатной температуре, гидромодуле, равном 5, и перемешивании. Продолжительность каждой промывки составляла 45 мин. Остатки щелочи в подложке нейтрализовали $0,1 \mathrm{~N}$ раствором $\mathrm{HNO}_{3}$ при гидромодуле 5 в течение 30 мин. После отделения раствора кислоты подложку двукратно промывали водой при гидромодуле 4 в течение 30 мин. Промывные воды удаляли фильтрованием. Полученную подложку сушили до воздушно-сухого состояния при $50^{\circ} \mathrm{C}$.

Схема получения удобрения на основе пористой подложки из коры осины приведена на рис. 1 .

Нанесение $\mathrm{KH}_{2} \mathrm{PO}_{4}$ на пористую подложку проводили пропиткой водным раствором соли. Объем пропиточного раствора $\left(1,9 \mathrm{~cm}^{3} / \Gamma\right)$ равен влагоемкости подложки, которую определяли по ГОСТ 24160-80. Концентрацию пропиточных растворов $\mathrm{KH}_{2} \mathrm{PO}_{4}$ рассчитывали так, чтобы удобрения содержали от 4,40 до 39,61 мас. \% фосфорнокалийной соли. Пропитку пористых материалов проводили при комнатной температуре небольшими порциями раствора соли и пере- 


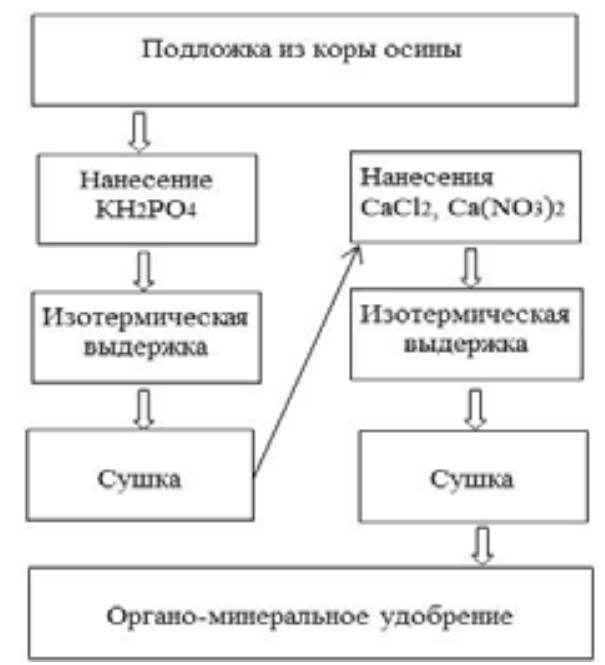

Рис. 1. Схема получения органо-минеральных удобрений на основе коры осины

Fig. 1. Schema of preparationof organo-mineral fertilizers based on aspen bark

мешивании. Затем влажную подложку помещали в закрытую посуду и выдерживали от 0,5 до 24 ч при комнатной температуре (изотермическая выдержка). Далее пропитанные подложки сушили при $100{ }^{\circ} \mathrm{C}$ до воздушно-сухого состояния.

Затем подложку, содержащую $\mathrm{KH}_{2} \mathrm{PO}_{4}$, пропитывали водным раствором соли кальция (хлорида или нитрата). Количество раствора соли кальция, требуемого для пропитки, также соответствовало влагоемкости подложки. Концентрацию пропиточных растворов выбирали так, чтобы варьировать мольное соотношение фосфора и кальция (Р:Са) от 1:0,5 до 1:3. Пропитанные образцы выдерживали в закрытых бюксах при комнатной температуре (изотермическая выдержка) в течение $8-30$ ч и затем сушили до воздушно-сухого состояния при $100{ }^{\circ} \mathrm{C}$.

На основе подложки, содержащей 22,05 мас. \% $\mathrm{KH}_{2} \mathrm{PO}_{4}$, аналогичным образом были приготовлены образцы удобрений с микроэлементами в количестве, мас. \%: $1,0 \mathrm{Mg}^{2+}, 0,1 \mathrm{Cu}^{2+}$, $0,1 \mathrm{Zn}^{2+}$ и $0,1 \mathrm{Fe}^{3+}$. Микроэлементы (железо в виде хлорида, остальные в сульфатной форме) в рассчитанном количестве добавляли в водный раствор фосфорнокалийной соли, и полученный раствор применяли для пропитки подложки. Удобрения были получены с использованием хлорида и нитрата кальция при соотношении Р:Са, равном 1:2,0. Изотермическая выдержка подложки, пропитанной раствором дигидрофосфата калия и микроэлементов, проводилась в течение 1 ч, а изотермическая выдержка после обработки растворами солей кальция - в течение 24 ч. Эти удобрения применяли при проведении вегетационных экспериментов.

Водостойкость полученных удобрений оценивали по вымыванию из них минеральных компонентов водой. Процесс вымывания проводили дистиллированной водой в стационарных условиях при комнатной температуре в течение суток по аналогии с методикой работы [7]. При изучении влияния продолжительности вымывания на выделение минеральных компонентов время контакта удобрений с водой составляло от 1 до 10 сут. Соотношение образца удобрения и воды при изучении вымывания равнялось 2 г к 500 мл. Количество калия, магния, меди, цинка и железа, перешедших в раствор, определяли атомно-эмиссионным и атомно-абсорбционным 
методами на приборе Analyst-400. Концентрацию фосфора в воде определяли методом массспектрометрии на приборе ICP-MS 7500 Agilent. Проводилось выборочное дублирование определений фосфора фотометрическим методом согласно ГОСТ 200851.2 - 75. По изменению концентрации минеральных компонентов в растворе рассчитывали величины их вымывания $(\%$,$) , принимая исходное количество этих элементов в образце удобрения за 100$ \%. Данные по вымыванию фосфатов и калия приведены в пересчете на $\mathrm{P}_{2} \mathrm{O}_{5}$ и $\mathrm{K}_{2} \mathrm{O}$.

Содержание в подложке лигнина (в модификации Комарова) и веществ, растворимых в $1 \% \mathrm{NaOH}$, определяли согласно общепринятым в химии древесины методикам [16].

Было проведено три варианта вегетационных экспериментов по изучению влияния органоминеральных удобрений из коры осины на проращивание и дальнейший рост семян листовой горчицы сорта «Веснушка»: контроль (500 г почвы); 500 г почвы + 10 г удобрения, полученного с использованием $\mathrm{CaCl}_{2} ; 500$ г почвы +10 г удобрения, полученного с использованием $\mathrm{Ca}\left(\mathrm{NO}_{3}\right)_{2}$. Удобрения были получены на основе подложки, содержащей 22,05 мас. \% $\mathrm{KH}_{2} \mathrm{PO}_{4}$ и микроэлементы в вышеуказанных количествах. В каждом опыте в почву было посеяно по 40 штук семян горчицы, выращивание проводили в течение 40 дней, при равномерном поливе и освещении. Колебание температуры в процессе выращивания не превышало $\pm 2{ }^{\circ} \mathrm{C}$. Результаты оценивали по всхожести семян, по длине растений и сухой фитомассе растений.

\section{Результаты и обсуждение}

Установлено, что обработка коры осины раствором щелочи позволяет получать пористую подложку с выходом 60,8 \%. Щелочной гидролиз приводит к существенному снижению количества остаточных веществ, способных к растворению в $1 \% \mathrm{NaOH}$, в подложке по сравнению с исходной корой - в 2,3 раза (табл. 1).

Достигаемое уменьшение содержания $\mathrm{BP}_{\mathrm{NaOH}}$ способствует повышению устойчивости подложки к гниению, поскольку присутствие этих веществ в растительных материалах характеризует их активность к микробиологической деградации (гниению) [16]. Это является важным критерием, определяющим целесообразность применения подложки для создания на ее основе удобрений с длительным сроком действия.

В результате щелочного гидролиза происходит развитие пористой структуры получаемой подложки, на что указывает увеличение показателя ее влагоемкости в 1,6 раза по сравнению с исходным сырьем (табл. 1). Поскольку нанесение минеральных компонентов на подложку осуществляется с учетом ее влагоемкости, от величины данного показателя зависит количество наносимых компонентов и равномерность их распределения по поверхности подложки [17].

Таблица 1. Свойства пористой подложки из коры осины

Table 1. Properties of porous support from aspen bark

\begin{tabular}{|l|c|c|c|}
\hline \multicolumn{1}{|c|}{ Образец } & ВЛ, г/г & $\mathrm{BP}_{\mathrm{NaOH}}, \%$ & Лигнин, \% \\
\hline Кора осины & 1,2 & 54,7 & 25,2 \\
\hline Пористая подложка из коры осины & 1,9 & 23,6 & 23,7 \\
\hline
\end{tabular}

$\mathrm{BP}_{\mathrm{NaOH}}-$ содержание веществ, растворимых в $1 \% \mathrm{NaOH}$, ВЛ - влагоемкость.

$$
-381-
$$


Таблица 2. Влияние количества $\mathrm{KH}_{2} \mathrm{PO}_{4}$ в удобрении на вымывание фосфатов и калия водой Table 2. The influence of the $\mathrm{KH}_{2} \mathrm{PO}_{4}$ amount in fertilizer on the phosphates and potassium leachingby water

\begin{tabular}{|c|c|c|c|c|}
\hline \multirow{2}{*}{$\begin{array}{c}\text { Содержание } \\
\text { КН }\end{array} \mathrm{PO}_{4}$, мас. \% } & \multicolumn{3}{|c|}{ Вымывание фосфатов и калия из удобрения на основе коры осины, \% * } \\
\cline { 2 - 5 } & \multicolumn{2}{|c|}{ Без пропитки $\mathrm{CaCl}_{2}$} & \multicolumn{2}{|c|}{ После пропитки $\mathrm{CaCl}_{2}$ ** } \\
\cline { 2 - 5 } & Вымывание $\mathrm{P}_{2} \mathrm{O}_{5}, \%$ & Вымывание $\mathrm{K}_{2} \mathrm{O}, \%$ & Вымывание $\mathrm{P}_{2} \mathrm{O}_{5}, \%$ & Вымывание $\mathrm{K}_{2} \mathrm{O}, \%$ \\
\hline 4,40 & 84,7 & 86,8 & 35,2 & 37,5 \\
8,80 & 83,5 & 86,1 & 28,4 & 34,2 \\
22,05 & 83,2 & 85,3 & 27,5 & 33,8 \\
30,81 & 83,2 & 85,9 & 27,6 & 33,9 \\
39,61 & 85,8 & 88,4 & 39,3 & 41,2 \\
\hline
\end{tabular}

*\% от исходного количества, ** кальцинированное удобрение.

Благодаря содержанию лигнина, полученная подложка из коры осины является источником ценных органических веществ, которые переходят в почву в результате биоразложения удобрения на ее основе.

Получение водостойкого удобрения на основе пористой подложки из коры осины состоит из двух основных стадий: нанесение на подложку фосфорнокалийной соли $\left(\mathrm{KH}_{2} \mathrm{PO}_{4}\right)$ и последующей пропитки этой подложки раствором хлорида или нитрата кальция (кальцинирование) (рис. 1). Основным процессом, приводящим к повышению водостойкости удобрения, является превращение $\mathrm{KH}_{2} \mathrm{PO}_{4}$ в менее растворимое соединение - $\mathrm{Ca}\left(\mathrm{H}_{2} \mathrm{PO}_{4}\right)_{2}$. Это позволяет существенно уменьшить вымывание водой из удобрений не только фосфатов, но и калия (табл. 2). Образцы удобрений, приведенных в табл. 2, получены при следующих условиях: изотермическая выдержка пропитанных фосфорнокалийной солью подложек 1 ч; кальцинирование при соотношении P:Са, равном 1:2, и изотермической выдержке до сушки в течение 24 ч.

Наибольший положительный эффект достигнут после кальцинирования подложек, содержащих от 8,80 до 30,81 мас. \% $\mathrm{KH}_{2} \mathrm{PO}_{4}$. Данный факт указывает на возможность варьирования количества фосфорнокалийной соли в удобрении без потери водостойкости.

Следует отметить, что для кальцинированных удобрений, независимо от количества нанесенного $\mathrm{KH}_{2} \mathrm{PO}_{4}$, наблюдается существенное уменьшение вымывания калия по сравнению с удобрениями, полученными без пропитки хлоридом кальция, - от 2,1 до 2,5 раз. Очевидно, частицы малорастворимого $\mathrm{Ca}\left(\mathrm{H}_{2} \mathrm{PO}_{4}\right)_{2}$ при осаждении заполняют поры подложки, создавая диффузионные затруднения вымыванию калия водой. Диффузионные процессы также могут способствовать уменьшению вымывания фосфатов из удобрений.

Важное влияние на формирование водостойкости получаемых удобрений может оказывать продолжительность изотермической выдержки пропитанной фосфорнокалийной солью подложки перед ее сушкой, влияющая на равномерность распределения нанесенного вещества по поверхности пористого носителя [17].

Было установлено, что увеличение времени выдержки от 1 до 24 ч не привело к уменьшению вымывания минеральных компонентов водой из получаемых удобрений (табл. 3).

Для удобрений, полученных без пропитки хлоридом кальция, вымывание минеральных компонентов мало меняется в результате увеличения времени выдержки. Однако визуальные наблюдения определили появление окраски водных растворов после контакта с образцами 
Таблица 3. Влияние продолжительности изотермической выдержки на вымывание фосфатов и калия из удобрений (пропитка раствором $\mathrm{CaCl}_{2}$ при соотношении $\mathrm{P}: \mathrm{Ca}$, равном 1:2, и изотермической выдержке до сушки в течение 24 ч)

Table 3. The influence of duration of a isothermal exposure on phosphates and potassium leaching from fertilizers (impregnating by the $\mathrm{CaCl}_{2}$ solutionat ratio $\mathrm{P}: \mathrm{C}$ aequal 1:2 and isothermal exposure before drying $24 \mathrm{~h}$ )

\begin{tabular}{|c|c|c|c|c|c|}
\hline \multirow{3}{*}{$\begin{array}{c}\text { Содержание } \\
\mathrm{KH}_{2} \mathrm{PO}_{4} \text {, мас. \% }\end{array}$} & \multirow{3}{*}{$\begin{array}{c}\text { Время } \\
\text { выдержки } \\
\text { до сушки, ч }\end{array}$} & \multicolumn{4}{|c|}{$\begin{array}{c}\text { Вымывание фосфатов и калия из удобрения } \\
\text { на основе коры осины, \%* }\end{array}$} \\
\hline & & \multicolumn{2}{|c|}{ Без пропитки $\mathrm{CaCl}_{2}$} & \multicolumn{2}{|c|}{ После пропитки $\mathrm{CaCl}_{2}{ }^{* *}$} \\
\hline & & $\begin{array}{c}\text { Вымывание } \\
\mathrm{P}_{2} \mathrm{O}_{5}, \%\end{array}$ & $\begin{array}{c}\text { Вымывание } \\
\mathrm{K}_{2} \mathrm{O}, \%\end{array}$ & $\begin{array}{c}\text { Вымывание } \\
\mathrm{P}_{2} \mathrm{O}_{5}, \%\end{array}$ & $\begin{array}{c}\text { Вымывание } \\
\mathrm{K}_{2} \mathrm{O}, \%\end{array}$ \\
\hline \multirow{4}{*}{8,80} & 0,5 & 88,9 & 88,7 & 36,5 & 39,7 \\
\hline & 1 & 83,5 & 86,1 & 28,4 & 34,2 \\
\hline & 4 & 83,7 & 86,5 & 28,8 & 34,5 \\
\hline & 24 & 83,8 & 86,8 & 30,1 & 35,6 \\
\hline \multirow{4}{*}{30,81} & 0,5 & 89,3 & 90,7 & 38,3 & 40,8 \\
\hline & 1 & 83,2 & 85,9 & 27,6 & 33,9 \\
\hline & 4 & 83,7 & 86,1 & 27,7 & 34,1 \\
\hline & 24 & 84,4 & 86,3 & 32,8 & 39,3 \\
\hline
\end{tabular}

* \% от исходного количества, ** кальцинированное удобрение.

удобрений, полученных в условиях 24-часовой выдержки перед их высушиванием. К этому может приводить взаимодействие фосфорнокалийной соли с органическими веществами подложки. Очевидно, такое взаимодействие снижает эффективность превращения $\mathrm{KH}_{2} \mathrm{PO}_{4}$ в малорастворимую форму. В результате для кальцированного удобрения увеличение продолжительности изотермической выдержки пропитанной фосфорнокалийной солью подложки от 1 до 24 ч приводит к увеличению вымывания фосфатов и калия в среднем на $5 \%$. Выдержка в течение 0,5 ч недостаточна для достижения равномерной пропитки полидисперсной пористой подложки раствором $\mathrm{KH}_{2} \mathrm{PO}_{4}$. Поэтому удобрения, полученные при такой продолжительности выдержки, демонстрируют наименьшую устойчивость к вымыванию фосфатов и калия водой (табл. 3).

Поскольку, как следует из табл. 2, перевод $\mathrm{KH}_{2} \mathrm{PO}_{4}$ в малорастворимую форму в результате его взаимодействия с хлоридом кальция является необходимым условием повышения водостойкости удобрения на основе подложки из коры осины, важно установить наиболее рациональные условия проведения этого процесса. На примере подложки, содержащей 30,81 мас. \% $\mathrm{KH}_{2} \mathrm{PO}_{4}$, изучено влияние мольного соотношения фосфора и кальция (Р:Са) на стадии ее пропитки раствором хлорида кальция и продолжительности последующей изотермической выдержки перед сушкой на вымывание фосфатов и калия из получаемых удобрений (рис. 2 и 3). Применяемая подложка после пропитки раствором фосфорнокалийной соли была выдержана при комнатной температуре в течение 1 ч перед последующей сушкой.

На рис. 2 показано, что максимально возможное уменьшение вымывания фосфатов и калия достигается при мольном соотношении Р:Са не менее 1:2,0. Применение большего количества хлорида кальция нецелесообразно, поскольку не влияет на водостойкость удобрений.

Для достижения наибольшего эффекта требуется длительная изотермическая выдержка (не менее 24 ч) пропитанного хлоридом кальция удобрения перед его сушкой (рис. 3). Это сви- 


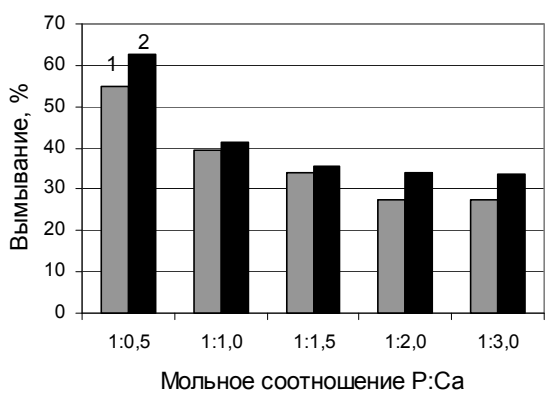

Рис. 2. Влияние мольного соотношения фосфора и кальция (Р:Са) на вымывание фосфатов (1) и калия (2) водой из удобрений на основе подложки из коры осины

Fig. 2. The influence of aphosphorus to calcium molar ratio ( $\mathrm{P}: \mathrm{Ca}$ ) on the phosphates (1) and potassium (2) leaching by water from fertilizers based on the support from aspen bark

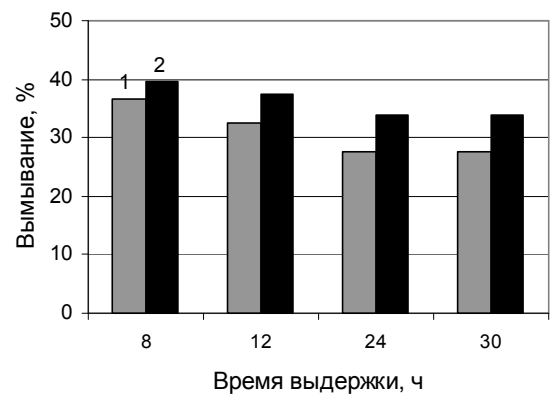

Рис. 3. Влияние времени изотермической выдержки после пропитки раствором хлорида кальция на вымывание фосфатов (1) и калия (2) из удобрения на основе подложки из коры осины

Fig. 3. The influence of anisothermal exposure time after impregnation by chloride calciumon the phosphates (1) and potassium (2) leaching by water from fertilizers based on the support from aspen bark

детельствует о медленном превращении $\mathrm{KH}_{2} \mathrm{PO}_{4}$ в $\mathrm{Ca}\left(\mathrm{H}_{2} \mathrm{PO}_{4}\right)_{2}$ на поверхности пористой подложки из коры осины. Более продолжительная выдержка не приводит к увеличению устойчивости удобрения к вымыванию водой минеральных компонентов. Можно предположить, что 24 ч выдержки достаточно для наиболее полного завершения процесса превращения фосфорнокалийной соли в целевое малорастворимое соединение.

Сопоставление данных табл. 3 , рис. 2 и 3 позволило определить условия, дающие возможность получать на основе подложки из коры осины удобрения с наибольшей устойчивостью к вымыванию минеральных компонентов: продолжительность изотермической выдержки подложки, пропитанной раствором $\mathrm{KH}_{2} \mathrm{PO}_{4}$, перед сушкой в течение 1 ч; пропитка раствором соли кальция при мольном соотношении Р:Са, равном 1:2,0; последующая изотермическая выдержка в течение 24 ; температура сушки $100{ }^{\circ} \mathrm{C}$. Реализация этих условий позволяет получать удобрения с различным содержанием фосфорнокалийной соли - от 8,80 до 30,81 мас. \% без потери их водостойкости.

Высушивание пропитанной раствором $\mathrm{KH}_{2} \mathrm{PO}_{4}$ подложки и удобрения на ее основе целесообразно проводить при температуре $100{ }^{\circ} \mathrm{C}$. Повышение температуры сушки до $170{ }^{\circ} \mathrm{C}$ (выше этой температуры наблюдалось осмоление подложки и понижение ее механической прочности) не приводит к увеличению водостойкости удобрений. Уменьшение температуры высушивания сопровождается незначительным увеличением вымывания фосфатов (не более 5 \%), но оказывает более существенное влияние на вымывание калия. Так, из удобрения, полученного при температуре $50{ }^{\circ} \mathrm{C}$ на обеих стадиях сушки (рис. 1), вымывается водой до 62,5 \% калия.

На основе подложки из коры осины, содержащей 22,05 мас. $\% \mathrm{KH}_{2} \mathrm{PO}_{4}$, при соблюдении вышеуказанных условий были получены удобрения, содержащие микроэлементы (мас. \%) $1,0 \mathrm{Mg}^{2+}, 0,1 \mathrm{Cu}^{2+}, 0,1 \mathrm{Zn}^{2+}$ и $0,1 \mathrm{Fe}^{3+}$. По содержанию микроэлементов получаемые удобрения приближены к промышленным гранулированным удобрениям, выпускаемым ЗАО «Фертика» (Россия). 
Таблица 4. Вымывание минеральных компонентов водой из органоминеральных удобрений на основе коры осины (исходное содержание $\mathrm{KH}_{2} \mathrm{PO}_{4}$ в удобрениях 22,05 мас. \%, P:Ca -1:2)

Table 4. The leaching of mineral components by water from organo-mineral fertilizers based on the support from aspen bark $\left(\mathrm{KH}_{2} \mathrm{PO}_{4}\right.$ origin content in fertilizers 22,05 mass \%, $\left.\mathrm{P}: \mathrm{Ca}-1: 2\right)$

\begin{tabular}{|c|c|c|c|c|c|c|}
\hline \multirow[t]{2}{*}{ Микроэлементы, мас. \% } & \multicolumn{3}{|c|}{$\begin{array}{c}\text { Вымывание фосфатов, } \\
\qquad \mathrm{P}_{2} \mathrm{O}_{5}, \% *\end{array}$} & \multicolumn{3}{|c|}{ Вымывание калия, $\mathrm{K}_{2} \mathrm{O}$, \%* } \\
\hline & 1 сут & 4 сут & 10 сут & 1 сут & 4 сут & 10 сут \\
\hline \multicolumn{7}{|c|}{ Удобрения, полученные с использованием $\mathrm{CaCl}_{2}$} \\
\hline Нет & 27,5 & 30,7 & 34,5 & 33,8 & 36,6 & 40,4 \\
\hline $1,0 \mathrm{Mg}^{2+}, 0,1 \mathrm{Cu}^{2+}, 0,1 \mathrm{Zn}^{2+}, 0,1 \mathrm{Fe}^{3+}$ & 27,4 & 30,9 & 34,7 & 37,8 & 38,8 & 41,0 \\
\hline \multicolumn{7}{|c|}{ Удобрения, полученные с использованием $\mathrm{Ca}\left(\mathrm{NO}_{3}\right)_{2}$} \\
\hline Нет & 27,6 & 30,8 & 34,5 & 33,7 & 36,8 & 40,6 \\
\hline $1,0 \mathrm{Mg}^{2+}, 0,1 \mathrm{Cu}^{2+}, 0,1 \mathrm{Zn}^{2+}, 0,1 \mathrm{Fe}^{3+}$ & 27,8 & 30,7 & 34,8 & 37,9 & 38,7 & 40,9 \\
\hline
\end{tabular}

*\% от исходного количества.

Введение в состав удобрений микроэлементов не приводит к изменению вымывания водой фосфатов, но увеличивает вымывание калия в течение 1 и 4 сут (табл. 4). Затем вымывание калия выравнивается, и через 10 сут в удобрениях остается примерно одинаковое количество этого компонента - не менее 59 мас. \%. При этом остаточное содержание фосфатов в удобрениях составляет не менее 65,2 мас. \% .

Было установлено, что природа соли кальция, используемой для получения удобрений, практически не влияет на вымывание фосфатов и калия - отличия этих показателей для образцов, полученных с использованием $\mathrm{CaCl}_{2}$ и $\mathrm{Ca}\left(\mathrm{NO}_{3}\right)_{2}$, не превышают в среднем $\pm 0,4 \%$. Однако применение нитрата кальция более предпочтительно, поскольку позволяет вводить в удобрение азот.

Эксперимент по вымыванию микроэлементов водой из удобрения, полученного с применением нитрата кальция, в течение 10 сут показал, что наибольшее количество этих компонентов вымывается из удобрения в первые сутки. При этом по величине вымывания магний превосходит другие микроэлементы. Затем вымывание исследуемых компонентов существенно замедляется, а через 10 сут из удобрения вымывается больше меди и цинка по сравнению с другими элементами (рис. 4).

Было установлено, что различия в величинах вымывания микроэлементов водой из удобрений, полученных с помощью хлорида и нитрата кальция, не превышают $\pm 0,5 \%$. Через 10 сут в удобрениях остается не менее 36,6 \% магния, 34,5 \% меди, 34,6 \% цинка и 37,6 железа (\% от исходного количества).

Сравнение данных табл. 4 и рис. 4 показывает, что разработанные удобрения характеризуются способностью к медленному вымыванию в течение длительного времени не только фосфатов и калия, но и микроэлементов. Это свидетельствует об эффекте пролонгированного действия удобрений на основе коры осины.

В вегетационных экспериментах на примере листовой горчицы сорта «Веснушка» выявлено ростостимулирующее действие органоминеральных удобрений на основе коры осины (табл. 5 и рис. 5, период выращивания горчицы 40 дней). Испытанные удобрения были получе-

$$
-385-
$$




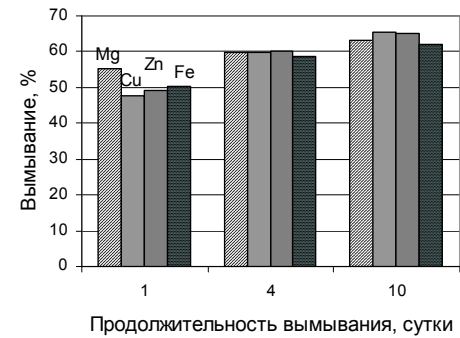

Рис. 4. Вымывание микроэлементов из удобрения на основе коры осины, полученного с использованием $\mathrm{Ca}\left(\mathrm{NO}_{3}\right)_{2}$ (исходное содержание $\mathrm{KH}_{2} \mathrm{PO}_{4}$ $22,05$ мас. $\%)$

Fig. 4. Theleaching of microelements from fertilizers based on aspen bark obtained with use of $\mathrm{Ca}\left(\mathrm{NO}_{3}\right)_{2} \quad\left(\mathrm{KH}_{2} \mathrm{PO}_{4}\right.$ origin content in fertilizers 22,05 mass \%)

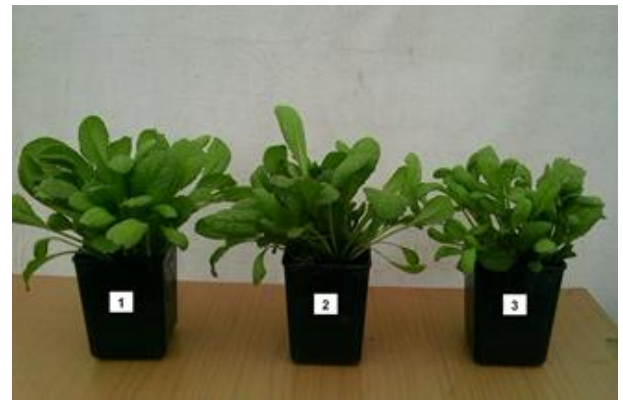

Рис. 5. Результаты выращивания листовой горчины сорта «Веснушка»: 1 - в присутствии удобрения на основе коры осины, полученного с использованием $\mathrm{Ca}\left(\mathrm{NO}_{3}\right)_{2} ; 2$ - в присутствии удобрения, полученного с использованием $\mathrm{CaCl}_{2} ; 3$ - контроль (без удобрений)

Fig. 5. The results of mustard leaf sort "Freckles" cultivation: 1 - inthepresence of a fertilizer obtained with use of $\mathrm{Ca}\left(\mathrm{NO}_{3}\right)_{2}$; 2 - in the presence of a fertilizer obtained with use of $\mathrm{CaCl}_{2}$; 3 - control (without fertilizers)

Таблица 5. Влияние органоминеральных удобрений (ОМУ) на основе коры осины на рост листовой горчицы сорта «Веснушка»

Table 5.The influence of organo-mineral fertilizers (OMY) based on aspen bark on the growth a mustard leaf sort «Freckles»

\begin{tabular}{|l|c|c|c|}
\hline \multicolumn{1}{|c|}{ Вариант опыта } & Всхожесть, \% & $\begin{array}{c}\text { Длина растений, } \\
\mathrm{X} \pm \mathrm{Sx}, \mathrm{cm}\end{array}$ & $\begin{array}{c}\text { Сухая фитомасса } \\
\text { растений, г/сосуд }\end{array}$ \\
\hline Почва - контроль* & 92 & $10,5 \pm 1,5$ & 5,35 \\
\hline $\mathrm{OMУ,} \mathrm{полученное} \mathrm{с} \mathrm{использованием} \mathrm{CaCl}_{2}$ & 92 & $13,7 \pm 1,1$ & 7,03 \\
\hline $\begin{array}{l}\text { ОМУ, полученное с } \\
\text { использованиемСа }\left(\mathrm{NO}_{3}\right)_{2}\end{array}$ & 93 & $16,8 \pm 1,2$ & 9,76 \\
\hline
\end{tabular}

* без удобрений, $\mathrm{X}$ - среднее значение, $\mathrm{Sx}$ - стандартная ошибка среднего.

ны на основе подложки, содержащей 22,05 мас. \% $\mathrm{KH}_{2} \mathrm{PO}_{4}$. Содержание в них микроэлементов составляло, мас. \%: $1,0 \mathrm{Mg}^{2+}, 0,1 \mathrm{Cu}^{2+}, 0,1 \mathrm{Zn}^{2+}$ и 0,1 $\mathrm{Fe}^{3+}$. Удобрение, полученное с использованием $\mathrm{CaCl}_{2}$ (соотношение Р:Са равно 1:2,0), содержало, мас. \%: 4,69 $\mathrm{K}_{2} \mathrm{O}, 7,08 \mathrm{P}_{2} \mathrm{O}_{5}, 11,09 \mathrm{CaO}, 14,04$ $\mathrm{Cl}$. Удобрение, полученное с использованием $\mathrm{Ca}\left(\mathrm{NO}_{3}\right)_{2}$ при тех же условиях, содержало, мас. \%: $5,14 \mathrm{~K}_{2} \mathrm{O}, 7,75 \mathrm{P}_{2} \mathrm{O}_{5}, 12,13 \mathrm{CaO}, 6,06 \mathrm{~N}$. Остальное количество приходилось на подложку из коры осины.

Выявлено, что внесение в почву удобрений на основе коры осины приводит к существенному увеличению длины растений и их фитомассы по сравнению с контрольным опытом. Применение удобрения, содержащего азот в нитратной форме, дает наибольшее увеличение этих показателей по сравнению с контролем - в 1,6 и 1,8 раза увеличивается длина растений и сухая фитомасса горчицы соответственно. За счет содержания азота достигается большее ростостимулирующее действие в сравнение с удобрением, содержащим в своем составе хлор. Всхожесть семян в присутствии удобрений не уступает их всхожести в контрольном опыте (табл. 5).

$$
-386-
$$




\section{Заключение}

Разработан способ получения фосфорных органоминеральных удобрений с повышенной устойчивостью к вымыванию водой фосфатов и калия. Показано, что метод превращения дигидрофосфата калия в менее растворимый дигидрофосфат кальция на поверхности подложки из коры осины позволяет уменьшить вымывание фосфатов в 3 раза, а калия в 2,5 раза. Выявлено, что природа соли кальция не влияет на водостойкость получаемых удобрений, но использование нитрата кальция предпочтительно, поскольку дает возможность вводить в удобрение до 6,06 мас. \% азота.

Определены условия, позволяющие получать удобрения с максимальной устойчивостью к вымыванию водой минеральных компонентов: количество наносимого на подложку $\mathrm{KH}_{2} \mathrm{PO}_{4}$ 8,80 - 30,81 мас. \%; продолжительность изотермической выдержки пропитанной подложки 1 ч; последующая пропитка раствором соли кальция при мольном соотношении Р:Са, равном 1:2,0; изотермическая выдержка удобрения перед сушкой в течение 24 ч; сушка при $100{ }^{\circ} \mathrm{C}$. Показана возможность введения в удобрения, полученные в этих условиях, различных микроэлементов ( $\mathrm{Mg}, \mathrm{Cu}, \mathrm{Zn}, \mathrm{Fe})$ без потери их водостойкости. Установлено, что через 10 сут вымывания водой в удобрениях остается не менее 65,2 \% фосфатов, 59 \% калия, 36,6 \% магния, 34,5 \% меди, 34,6 \% цинка и 37,6 железа (\% от их исходного количества). Это свидетельствует об эффекте пролонгированного действия органоминеральных удобрений на основе коры осины.

В результате экспериментов по выращиванию листовой горчицы сорта «Веснушка» установлено ростостимулирующее действие фосфорных органоминеральных удобрений на основе коры осины.

\section{Список литературы}

1. Кузнецов Б.Н., Левданский В.А., Кузнецова С.А. Химические продукты из древесной коры: монография. Красноярск: Сиб. фед. ун-т, 2012. 260 с. [Kuznetsov B.N., Levdanskiy V.A., Kuznetsova S.A. Chemical products of woody-crust: monograph. Krasnoyarsk: Siberian Federal University, 2012. 260 p. (in Russ.)]

2. Pasztory Z., Mohacsine I.R., Gorbacheva G., Borcsok Z.. The utilization of tree bark. BioResources 2016. Vol. 11(3), P. 7859-7888.

3. Хохотва А.П. Адсорбция тяжелых металлов сорбентом на основе сосновой коры. $Х u$ мия и технология воды 2010. Т. 32(6), С. 604-612. [Khokhotva O.P. Sorption of heavy metals on a sorbent based on pine bark. J. of Water Chemistry and technology 2010. Vol. 32(6), P. 604-612. (in Russ.)]

4. Кузнецова С.А., Кузнецов Б.Н., Скурыдина Е.С., Максимов Н.Г., Калачева Г.С., Ульянова О.А., Скворцова Г.П. Синтез и свойства биокомпозитных удобрений на основе мочевины и коры березы. Журнал Сибирского федерального университета. Химия 2013. Т. 6 (4), C. 380-393. [Kuznetsova S.A., Kuznetsov B.N., Skurydina E.S., Maksimov N.G., Kalachova G.S, Ulyanova O.A., Skvortsova C.P. Synthesis and properties of biocomposite fertilizerson the basis of urea and birch bark. Journal of Siberian Federal University. Chemistry 2013. Vol. 6 (4), P. 380-393. (in Russ.)]

5. Патент 2502713 РФ. Кожевникова Н.М Торфоцеолитовое удобрение пролонгированного действия, модифицированное фосфатом калия. Опубл. 27.12.2013. [Patent 2502713 RU.

$$
-387-
$$


Kojevnikova N.M. The peat-zeolite fertilizer of long - time action modified by potassium phosphate. Publ. Date 27.12.2013 (in Russ.)]

6. Rajonee A.A., Zaman S., Huq, S.M.I. (2017) Preparation, Characterization and Evaluation of Efficacy of Phosphorus and Potassium Incorporated Nano Fertilizer. Advances in Nanoparticles 2017. Iss. 6, P. 62-74.

7. Sheikh Ali Ahmed, Jong In Kim, Kyung Mi Park, Su Kyoung Chun. Ammonium nitrateimpregnated woodchips: a slow-release fertilizer for plants. J. Wood Science. 2011. Vol. 57, P. 295301.

8. Дабахов М.В., Дабахова Е.В., Титова В.И. Тяжелье металлы: экотоксикология и проблемы нормирования. Н. Новгород: Изд-во ВВАГС, 2005. 165 с. [Dabaxov M.V., Dabaxova E.V., Titova V.I. Heavy metals: Ecotoxicology and problems of rationing. N. Novgorod: Publising VVAGS, 2005. 105 p. (in Russ.)]

9. Заришняк А.С., Иванина В.В., Калибабчук Т.В. Фосфатный режим чернозема оподзоленного при длительном применении удобрений. Агрохимия 2014. № 4, С. 20-26. [Zaryshnyak A.S., Ivanina V.V., Kolibabchuk T.V. Phosphate status of podzolized chernozem under long-term fertilization. Agricultural Chemistry 2014. No. 4, P. 20-26. (in Russ.)]

10. Самсонова Н.Е., Родченков С.Н. Использование удобрений с пониженной растворимостью фосфатного компонента и фосфатное состояние дерново-подзолистых почв. Агрохимия 2007. № 9, C. 24-31. [Samsonova N.T., Rodchenkov S.V. The use of partially soluble phosphate fertilizers and the phosphate status of soddy-podzolic soils. Agricultural Chemistry 2007. No. 9, P. 24 31. (in Russ.)]

11. Adesh Kumar Efficiency of Modified Phosphatic Fertilizer in Transplanted Rice (Oryza sativa L.) Under Partially Reclaimed Salt Affected Soil of Uttar Pradesh. National Science Letters 2017. Vol. 40 (1), P. 5-7.

12. Веприкова Е.В., Кузнецова С.А., Чесноков Н.В., Кузнецов Б.Н. Получение и свойства фосфорных биокомпозитных удобрений на основе коры березы. Журнал Сибирского федерального университета. Химия 2015. T. 8 (3), C. 413-421. [Veprikova E.V., Kuznetsova S.A., Chesnokov N.V., Kuznetsov B.N. Preparation and Properties of Phosphorus Biocomposite Fertilizers Based on the Birch Bark. Journal of Siberian Federal University. Chemistry 2015. T. 8 (3), P. 413-421. (in Russ.)]

13. Веприкова Е.В., Королькова И.В., Чесноков Н.В., Кузнецов Б.Н. Влияние свойств пористых подложек на устойчивость биокомпозитных удобрений к вымыванию калия и фосфора. Журнал Сибирского федерального университета. Химия 2017. Т. 10 (2), С. 226-238. [Veprikova E.V., Korolkova I.V., Chesnokov N.V., Kuznetsov B.N. Effect of the Porous Supports Propertieson the Biocomposite Fertilizers Resistantto Leaching of Potassium and Phosphates. Journal of Siberian Federal University. Chemistry 2017. T. 10(2), Р. 226-238. (in Russ.)]

14. Веприкова Е.В., Кузнецов Б.Н., Чесноков Н.В. Получение биокомпозитных фосфоркалийных удобрений пролонгированного действия на основе коры лиственницы. Химия растительного сырья 2017. № 3, С. 201-209. [Veprikova E.V., Kuznetsov B.N., Chtsnokov N.V. Preparation of biocomposite phosphorus-potassium fertilizers with long-time action on the base of a larch bark. Chemistry of plant raw materials 2017. No. 3, P. 201-209. (in Russ.)]

15. Patent CN 106748192 (A). Wu Guangwei. Tea planting fertilizer adsorbing organic fermentation product and preparating method thereof. Publ. Date 31.05.2017. 
16. Оболенская А.В., Ельницкая 3.П., Леонович А.А. Лабораторные работы по химии древесины и иеллюлозы. М.: Экология, 1991. 320 с. [Obolenskaya A.V., Elnitskaya Z.P., Leonovich A.A. Laboratory works on wood and cellulose chemistry: Textbook for high schools. M.: Ecology, 1991. 320 P. (in Russ.)]

17. Alvin B. Stiles Catalyst Supports and Supported Catalysts: Theoretical and Applied Concepts. Butterworth Publishers, Stoneham, MA. 1987. 270 p. 